\title{
Comparison of Genital Chlamydia trachomatis Infection Incidence Between Women With Infertility and Healthy Women in Iran Using PCR and Immunofluorescence Methods
}

\author{
Seyed Mahmoud Amin Marashi ${ }^{1}$;Zahra Moulana ${ }^{2}$; Abbas Ali Imani Fooladi ${ }^{3,{ }^{*}}$; Mohammad \\ Mashhadi Karim $^{3}$ \\ ${ }^{1}$ Department of Microbiology and Immunology, Alborz University of Medical Sciences, Karaj, IR Iran \\ ${ }_{2}^{2}$ Infectious Diseases and Tropical Medicine Research Center, Babol University of Medical Sciences, Babol, IR Iran \\ ${ }^{3}$ Applied Microbiology Research Center, Baqiyatallah University of Medical Sciences, Tehran, IR Iran \\ ${ }^{*}$ Corresponding author: Abbas Ali Imani Fooladi, Applied Microbiology Research Center, Baqiyatallah University of Medical Sciences, Tehran, IR Iran. Tel/Fax: +98-2188039883, E-mail: \\ imanifouladi.a@gmail.com, imanifouladi.a@bmsu.ac.ir
}

Received: December 3, 2012; Revised: May 13, 2013; Accepted: May 23, 2013

\begin{abstract}
Background: For a long time, infertility has been one of the most sequels in medical sciences with microbial agents as one group of its causes. The possible etiological role of Chlamydia trachomatis in infertility was suggested years ago, but it has not yet been proved completely. To decrease the severe involvements of $C$. trachomatis infections, screening by efficient diagnostic methods are necessary.

Objectives: In this study we attempted to determine the incidence of $C$. trachomatis in infertile women and compared this with healthy women.

Materials and Methods: This case-control study was performed on 150 infertile women with unknown causes and without physiological deficiency for infertility. The control group consisted of 200 fertile safe and impregnated women. Presence of $C$. trachomatis in the two groups was examined by direct and indirect immunofluorescence tests and PCR.

Results: C. trachomatis was detected by direct immunofluorescence method in $23(15.3 \%)$ infertile women compared and 7 (3.5\%) healthy controls. Using indirect immunofluorescence tests, a positive test titer of 1:16 as well as the above results were detected in 34 (22.6\%) of the infertile cases and 9 (4.5\%) of the controls. C. trachomatis was detected by PCR method in 48 (32\%) infertile women and $13(8.7 \%)$ among the controls.
\end{abstract}

Conclusions: The results of our study suggest that there is a significant association between C. trachomatis infection and female infertility.

Keywords:Chlamydia trachomatis; Infertility; Women; Iran

\section{Background}

Urogenital infections are caused by Chlamydia trachomatis worldwide (1). This bacterium is the most prevalent cause of bacterial sexually transmitted diseases (STD). The prevalence of these infections can be different depending on the country and population type. The prevalence of $C$. trachomatis infection among sexually active women in developing countries is higher than developed countries (2, 3). Annually, about one million C. trachomatis infections are reported among sexually active young women in the united states, according to the Center for Disease Control and Prevention (CDC) (4). Most of the infected individuals are asymptomatic; so, the majority of these infections are not detected and treated, and this can lead to pelvic inflammatory diseases, with bacteria reaching the upper genital tract of the infected women (5).

The etiological relation of pelvic inflammatory diseases (PIDs) with microorganisms is not completely determined; but, the presence of a variety of microorganisms including C. trachomatis, Mycoplasma genitalium, Neisseria gonorrhea and some other microorganisms have been shown in lower and upper genital tracts of women with PID (6-11). Nevertheless, C. trachomatis is more suspected than other sexually transmitted diseases to causes symptomatic PID $(9,12,13)$. PID can induce disorders such as infertility and ectopic pregnancy. These disorders may be the results of destruction of cilia layer of the fallopian and closure of fallopian tube (14). Therefore, detection and control of $C$. trachomatis infection prevalence is necessary to prevent its related sequels.

The duration of tubal inflammation and damages resulted from infection are two important factors affecting the efficiency of Chlamydia control programs. Therefore, it is important to detect and treat the infection before its development to short-term sequels such as pelvic inflammatory diseases, which in turn can develop into longterm sequels such as tubal factor infertility and ectopic 
pregnancy (15). In Iran, there are low epidemiological data regarding the prevalence of $C$. trachomatis infection and its consequences and it is clear that having more epidemiological knowledge about genital C. trachomatis infection prevalence could be very effective in choosing efficient strategies for screening and treatment of such infections.

\section{Objectives}

The purpose of this research was to determine the prevalence of $C$. trachomatis in healthy women and women with infertility disorder to evaluate the association between C. trachomatis infections and infertility in Iran.

\section{Materials and Methods}

\subsection{Population}

This research was a case-control study with 350 female participants. The case group consisted of 150 infertile women, 20 to 40 years, with no recognized physiological deficiency for infertility (unknown cause). The control group consisted of 200 impregnated women, 20 to 40 years, with one or more successful childbirths and without any history of infertility (Table 1).

\subsection{Specimen Collection}

Two types of specimens from the both case and control groups were used in this study including endocervical mucosa and blood serums. Sampling from endocervical mucosa was performed using the Pap smear method.

\subsection{Laboratory Methods}

Direct and indirect immunofluorescence methods were used for determining the presence or absence of $C$. trachomatis infection in both case and control groups. For direct testing, endocervical swabs were transferred on clean slides and the slides were incubated at room temperature for drying and fixation. One drop of antichlamydial monoclonal antibody (antibody-online, USA) was added to each slide and they were incubated at $37^{\circ} \mathrm{C}$ for 10 minutes. Then, the slides were washed with phosphate buffered saline (PBS) and distilled water for 10 and $5 \mathrm{~min}$ utes, respectively. Finally, the slides were examined for $C$. trachomatis by fluorescence microscopy (Micros, Austria).

Using this technique, the elementary bodies are observed as fluorescence green spots. For indirect testing, $C$. trachomatis serotypes D-K, L1-L3 and IOL-207 (TWAR) were used as standard antigens. The serotypes were individually grown in eggs and then placed on specific areas of the slides. A spot on the slide was also specified for the mixture of egg yolk in PBS (PAA, Holland) as a negative control. Serums in dilutions ranging from 1:16 to 1:256 were prepared and individually added to the slides. After
30 minutes of incubation at $37^{\circ} \mathrm{C}$, the slides were washed and stained with fluorescence antihuman globulin. Finally, the slides were examined by fluorescence microscopy and the results were recorded based on their color and fluorescence intensity (Table 2).

\subsection{PCR Mixture and DNA Amplification}

Endocervical swab samples were obtained from the patients. Each swab was placed in a sample collection vial containing the buffer (PBS). Several methods are available for DNA extraction. In the present study, we used the boiling method. We selected one pair of oligonucleotide primers (Cinnagen, Iran) specific for a region of the C. trachomatis gene (accession No. AB695165.1), coding for the major outer membrane protein (MOMP). The sequences from 5' to 3' of these oligonucleotide primers are as follows:

\section{Forward: 5'-CCTGTGGGGAATCCTGCTGAA-3'}

Revers: 5'-GTCGAAAACAAAGTCACCATAGTA-3'

A master mixture of these reagents was made for the samples along with the positive and negative controls. The final reaction mixture of $50 \mu \mathrm{L}$ for each sample contained $0.5 \mu \mathrm{M}$ of each primer; $100 \mu \mathrm{M}$ of each of dATP, dCTP, dGTP and dTTP; $50 \mathrm{mM} \mathrm{KCl} ; 10 \mathrm{mM}$ Tris-HCl, pH 8.3; $1.5 \mathrm{mM} \mathrm{MgCl}_{2}, 1.25$ units of Taq DNA polymerase enzyme, and $9 \mu \mathrm{L}$ of the sample DNA. All the PCR reagents were purchased from the SinaClon company, Iran. Each microfuge tube containing the PCR mixture of $50 \mu \mathrm{L}$ was mixed and subjected to 40 cycles of amplification. Each

Table 1. The Mean Age of Participants in the Case and Control Groups

\begin{tabular}{|c|c|c|}
\hline Age Groups & Case Group $(\mathbf{n}=150)$ & Control Group $(\mathbf{n}=\mathbf{2 0 0})$ \\
\hline 20 & 31 & 31 \\
\hline $20-24$ & 23 & 55 \\
\hline $25-29$ & 80 & 93 \\
\hline $30-34$ & 10 & 12 \\
\hline $35-39$ & 4 & 5 \\
\hline$>40$ & 2 & 4 \\
\hline Age average & 24.3 & 25.2 \\
\hline
\end{tabular}

Table 2. Determination of Positivity or Negativity of the Tests Based on the Fluorescence Intensity and Colors of Slides

\begin{tabular}{lc}
\hline Fluorescence Intensity and Color & Positivity or Negativity \\
\hline Very shiny green & ++ \\
Shiny green & ++ \\
Green & + \\
Yellowish green & \pm \\
Orange & - \\
\hline
\end{tabular}


cycle composed of sequential incubations at $94^{\circ} \mathrm{C}$ for 1 minute for DNA denaturation, $52^{\circ} \mathrm{C}$ for 1 minute for annealing the primer to the templates, and $72^{\circ} \mathrm{C}$ for 30 seconds for DNA chain extension. At the end of the 40 cycles, the samples were kept for another 7 minutes at $72^{\circ} \mathrm{C}$ for completion of the extension of a DNA chain. The PCR product samples were immediately frozen for further analysis. The PCR products were visualized by agarose gel electrophoresis. A10- $\mathrm{LL}$ post-PCR mixture was subjected to electrophoresis on $2 \%$ agarose gel (SinaClone, Iran) in the presence of ethidium bromide (Sigma, Germany). A DNA ladder (SinaClone, Iran) was also run simultaneously to confirm the size of the amplified product (103 bp) (Figure 1). The DNAs were extracted from the bands on the gel using a gel extraction kit (Qiagen, GmbH, Germany) and then sequenced by Macrogen Inc, Seoul, Korea.

\section{Results}

The results of direct and indirect immunofluorescence tests are shown in Table 3. As they show, the prevalence of C. trachomatis in the case and control groups reached to $15.3 \%$ and $3.5 \%$, respectively, using the direct immunofluorescence method. For the indirect immunofluorescence method, the prevalence of $C$. trachomatis reached to $22.6 \%$ and $4.5 \%$ in the case and control groups, respectively. In addition, the prevalence of $C$. trachomatis in the case and control groups reached to $32 \%$ and $8.7 \%$, respectively, using PCR method. The P values for direct and indirect immunofluorescence and PCR results were calculated by the Fisher test where a P value $<0.001$ for direct test results and $\mathrm{P}<0.004$ for indirect and PCR test results were obtained (Table 3 ).

\section{Discussion}

C. trachomatis is one of the most prevalent causes of sexually transmitted diseases. It is the major cause of urethritis and cervicitis, as well as their sequels such as PID and tubal factor infertility (16). Generally, Chlamydial infections are more destructive for reproductive health of women than men (5).

Svenstrup et al. reported that $23 \%$ of women suffering from tubal factor infertility (TFI) had antibodies against C. trachomatis, compared with $15 \%$ of women in the control group with normal tubes (17). In another research, Siemer et al. showed considerably higher prevalence of IgG and IgA antibodies (39\% and 14\%, respectively) among women with infertility compared with members of the control group (19\% and 3\%, respectively) (18). In a study carried out by Malik et al. the presence of $C$. trachomatis in infertile women was $28.1 \%$, which was significantly higher than that of healthy women $(3.3 \%)(\mathrm{P}<0.01)(19)$. Gaudoin et al. reported that $91.2 \%$ of woman with tubal occlusion had IgG antichlamydial antibodies in their sera (20).

Our results were compatible with the above studies.
Figure 1. Uniplex PCR for Detection of the MOMP Gene in Clinical Strains
of C. trachomatis

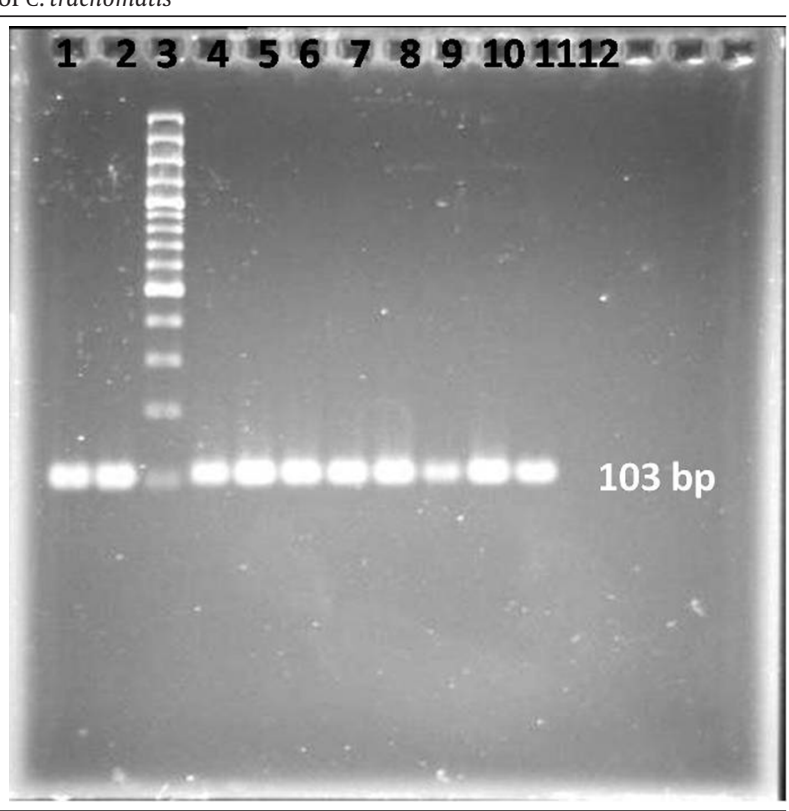

Lanes 1, 2, 4-10: clinical samples, lanes 11,12: positive and negative controls strains respectively, lane 3: molecular weight marker, 100-bp DNA.

Table 3. Results of Direct and Indirect Immunofluorescence and PCR Tests for Diagnosis of C. trachomatis in the Case and Control Groups

\begin{tabular}{lccc}
\hline Anti-Chlamydial Antibody Titer & Case Group Positives $(\mathbf{n}=\mathbf{1 5 0})$ & Control Group Positives $(\mathbf{n}=\mathbf{2 0 0})$ & Fisher Test Results \\
\hline Direct immunofluorescence & $23(15.3)$ & $7(3.5)$ & $\mathrm{P}<0.001$ \\
Indirect immunofluorescence & $10(6.6)$ & $5(2.5)$ & \\
\multicolumn{1}{|l}{$1: 16$} & & $2(1)$ & \\
$1: 32$ & $18(12)$ & $2(1)$ & $\mathrm{P}<0.004$ \\
\hline 1:64 & $6(4)$ & 0 & $13(8.7)$ \\
\hline PCR & 0 & & \\
\hline
\end{tabular}


In our study, the presence of $C$. trachomatis infection in the 150 infertile women with an average age of 24.3 years as the case group as well as 200 healthy women with an average age of 25.2 years as the control group was examined using direct and indirect immunofluorescence and PCR methods. In the direct immunofluorescence method, $15.3 \%$ of the case and $3.5 \%$ of the control group members showed positive results. The indirect immunofluorescence test also determined that $22.6 \%$ of the case and $4.5 \%$ of the control group members had a titer $\geq 1: 16$. The obtained P values from the results of direct and indirect immunofluorescence experiments by Fisher test were $\mathrm{P}<$ 0.001 and $\mathrm{P}<0.004$, respectively, confirming the significant association between urogenital chlamydial infections and infertility. The difference between the results of direct and indirect immunofluorescence tests could be due to old chlamydial infections or infections in other areas of the body.

Our results suggested that there was a significant association between C. trachomatis infection and female infertility. Therefore, $C$. trachomatis can be one of the main ethological factors for female infertility. Consequently, it is recommended that infertile women without any physiological deficiency should be examined for contamination with C. trachomatis. Finally, for detection of genital $C$. trachomatis, PCR results are more reliable than immunofluorescence tests.

\section{Acknowledgements}

We thank Dr. Barbara Lee Smith Pierce (University of Maryland, University College Scientific and Medical Editing Department, Baltimore, USA) for her editorial work in the preparation of this manuscript.

\section{Authors' Contribution}

Abbas Ali Imani Fooladi supervised, developed the Study concept, design and Critical revision of the manuscript; Seyed Mahmoud Amin Marashi researched and contributed to the development drafting of the manuscript and Critical revision of the manuscript; Zahra Moulana advised and contributed to design this research; Mohammad Mashhadi Karim was contributed to the development drafting of the manuscript and Critical revision of the manuscript.

\section{Financial Disclosure}

The authors declared no financial interests.

\section{Funding/Support}

The authors received no funding or support for this project.

\section{References}

1. Genuis SJ, Genuis SK. Managing the sexually transmitted disease pandemic: a time for reevaluation. Am J Obstet Gynecol. 2004;191(4):1103-12.

2. Gerbase AC, Rowley JT, Heymann DH, Berkley SF, Piot P. Global prevalence and incidence estimates of selected curable STDs. Sex Transm Infect. 1998;74 Suppl 1:S12-6.

3. Biendo M, Lefebvre JF, Fuentes V, Orfila J. [The prevalence of antiChlamydia trachomatis and anti-Chlamydia pneumoniae antibodies in Brazzaville]. Bull Soc Pathol Exot. 1994;87(2):85-8.

4. Essig A. Chlamydia and chlamydophila. In: Murray P. R. , Jorgensen J. H. , Landry M. L. , Pfaller M. A. editors. Manual of Clinical Microbiology.. Washington, DC: ASM Press; 2007.

5. Peipert JF. Clinical practice. Genital chlamydial infections. N Eng JMed. 2003;349(25):2424-30.

6. Haggerty CL, Hillier SL, Bass DC, Ness RB, P. I. D. Evaluation, Clinical Health study I. Bacterial vaginosis and anaerobic bacteria are associated with endometritis. Clin Infect Dis. 2004;39(7):990-5.

7. Haggerty CL. Evidence for a role of Mycoplasma genitalium in pelvic inflammatory disease. Curr Opin Infect Dis. 2008;21(1):65-9.

8. Hillier SL, Kiviat NB, Hawes SE, Hasselquist MB, Hanssen PW Eschenbach DA, et al. Role of bacterial vaginosis-associated microorganisms in endometritis. Am J Obstet Gynecol. 1996;175(2):435-41.

9. Ness RB, Soper DE, Holley RL, Peipert J, Randall H, Sweet RL, et al. Effectiveness of inpatient and outpatient treatment strategies for women with pelvic inflammatory disease: results from the Pelvic Inflammatory Disease Evaluation and Clinical Health (PEACH) Randomized Trial. Am J Obstet Gynecol. 2002;186(5):929-37.

10. Ness RB, Kip KE, Hillier SL, Soper DE, Stamm CA, Sweet RL, et al. A cluster analysis of bacterial vaginosis-associated microflora and pelvic inflammatory disease. Am J Epidemiol. 2005;162(6):585-90.

11. Simms I, Eastick K, Mallinson H, Thomas K, Gokhale R, Hay P, et al. Associations between Mycoplasma genitalium, Chlamydia trachomatis and pelvic inflammatory disease. I Clin Pathol. 2003;56(8):616-8.

12. Heinonen PK, Miettinen A. Laparoscopic study on the microbiology and severity of acute pelvic inflammatory disease. Eur J Obstet Gynecol Reprod Biol.1994;57(2):85-9.

13. Ness RB, Randall H, Richter HE, Peipert JF, Montagno A, Soper DE, et al. Condom use and the risk of recurrent pelvic inflammatory disease, chronic pelvic pain, or infertility following an episode of pelvic inflammatory disease. Am J Public Health. 2004;94(8):1327-9.

14. Haggerty CL, Gottlieb SL, Taylor BD, Low N, Xu F, Ness RB. Risk of sequelae after Chlamydia trachomatis genital infection in women. J Infect Dis. 2010;201 Suppl 2:S134-55.

15. Stamm W. Chlamydia trachomatis infections in the adult. In: Holmes K, Sparling P, WE S editors. Sexually transmitted diseases. New York: McGraw Hill Medical; 2008. pp. 575-94.

16. Millman K, Black CM, Johnson RE, Stamm WE, Jones RB, Hook EW, et al. Population-based genetic and evolutionary analysis of Chlamydia trachomatis urogenital strain variation in the United States.J Bacteriol. 2004;186(8):2457-65.

17. Svenstrup HF, Fedder J, Kristoffersen SE, Trolle B, Birkelund S, Christiansen G. Mycoplasma genitalium, Chlamydia trachomatis, and tubal factor infertility-a prospective study. Fertil Steril. 2008;90(3):513-20

18. Siemer J, Theile O, Larbi Y, Fasching PA, Danso KA, Kreienberg R, et al. Chlamydia trachomatis infection as a risk factor for infertility among women in Ghana, West Africa. Am J Trop Med Hyg. 2008;78(2):323-7

19. Malik A, Jain S, Hakim S, Shukla I, Rizvi M. Chlamydia trachomatis infection \& female infertility. Indian J Med Res. 2006;123(6):770-5.

20. Gaudoin M, Rekha P, Morris A, Lynch J, Acharya U. Bacterial vaginosis and past chlamydial infection are strongly and independently associated with tubal infertility but do not affect in vitro fertilization success rates. Fertil Steril.1999;72(4):730-2. 